OPEN ACCESS

Edited by:

Hasan Ayaz,

Drexel University, United States

Reviewed by:

Márk Molnár,

Institute of Cognitive Neuroscience and Psychology (MTA), Hungary

Kimmo Alho,

University of Helsinki, Finland

*Correspondence:

Diana Henz

henz@uni-mainz.de

Received: 08 November 2018 Accepted: 21 March 2019

Published: 12 April 2019

Citation:

Henz D and Schöllhorn WI (2019) Dynamic Office Environments Improve Brain Activity and Attentional Performance Mediated by Increased Motor Activity.

Front. Hum. Neurosci. 13:121. doi: 10.3389/fnhum.2019.00121

\section{Dynamic Office Environments Improve Brain Activity and Attentional Performance Mediated by Increased Motor Activity}

\section{Diana Henz* and Wolfgang I. Schöllhorn}

Institute of Sports Science, Faculty of Social Sciences, Media and Sport, Johannes Gutenberg University Mainz, Mainz, Germany

Current research demonstrates beneficial effects of physical activity on brain functions and cognitive performance. To date, less is known on the effects of gross motor movements that do not fall into the category of sports-related aerobic or anaerobic exercise. In previous studies, we found beneficial effects of dynamic working environments, i.e., environments that encourage movements during cognitive task performance, on cognitive performance and corresponding brain activity. Aim of the present study was to examine the effects of working in a dynamic and a static office environment on attentional and vigilance performance, and on the corresponding electroencephalographic (EEG) brain oscillatory patterns. In a 2-week intervention study, participants worked either in a dynamic or a static office. In each intervention group, 12 subjects performed attentional and vigilance tasks. Spontaneous EEG was measured from 19 electrodes continuosly before, during, and immediately after each experimental condition at the first, and at the last intervention session. Results showed differences in EEG brain activity in the dynamic compared to the static office at the beginning as well as at the end of the intervention. EEG theta power increased in the vigilance task in anterior regions, alpha power in central and parietal regions in the dynamic compared to the static office. Further, increases in beta activity in the attention and vigilance task were shown in frontal and central regions in the dynamic office. Gamma power increased in the attention task in frontal and central regions. After 2 weeks, effects on brain activity increased in the attentional and vigilance task in the dynamic office. Increased theta and alpha oscillations were obtained in anterior areas with higher activity in the beta band in anterior and central areas in the dynamic compared to the static office. EEG oscillatory patterns indicate beneficial effects of dynamic office environments on attentional and vigilance performance that are mediated by increased motor activity. We discuss the obtained patterns of EEG oscillations in terms of the close interrelations between the attentional and the motor system.

Keywords: ergonomics, office, movement, dynamic working environment, EEG 


\section{INTRODUCTION}

Research demonstrates beneficial effects of bodily movement on brain and cognitive functions. Most studies performed in this area investigate the effects of aerobic exercise and gross motor movements on cognitive functions (for meta-analytic overviews see Etnier et al., 2004; Chang et al., 2012; Gheysen et al., 2018; Mandolesi et al., 2018). More specifically, beneficial effects of physical exercise have been demonstrated on brain and cognitive functions such as increased gray matter volume in frontal and hippocampal volume (Colcombe et al., 2006), increased neurotrophic factor (Brunoni et al., 2008), increased blood flow (Weinberg and Gould, 2015), increasing in academic achievement (Sibley and Etnier, 2003), improvements in cognitive functions such as memory abilities, efficiency of attentional and executive-control processes (Kramer et al., 1999; Colcombe and Kramer, 2003; Grego et al., 2005; Pereira et al., 2019; Winter et al., 2007; Chieffi et al., 2017), prevention of cognitive decline (Colberg et al., 2008), reduced risk developing dementia, and a modified network topology (Deeny et al., 2008). Examining the underlying neurophysiological processes, physical exercise induces most often changes in electroencephalographic (EEG) alpha and beta bands (Moraes et al., 2007, 2011). Further, changes in brain activity are dependent on the type and intensity of the physical exercise (Brümmer et al., 2011).

Less is known on the effects of gross motor movements on the cognitive system that do not fall into the categorization of aerobic or anaerobic exercise. In previous studies, we investigated the effects of dynamic sitting on brain activity and cognitive performance. Participants performed arithmetic, geometric, and algebraic tasks either on a static chair that did not foster movements or on a dynamic chair that allowed subject-induced movements in the vertical and horizontal direction during task performance. We observed improvements in mathematical performance when sitting on a dynamic chair. More specifically, performance in geometric and algebraic tasks that afforded visuo-spatial processing increased. The corresponding EEG brain activity showed increases in overall alpha and beta activity in areas related to visuo-spatial processing. We concluded that dynamic sitting activates working memory processes that leads to better performance in visuo-spatial processing (Henz, 2014; Henz et al., 2015).

These findings encourage further developments from dynamic sitting furniture towards the design of office environments consisting of mobile chairs, desks, and floors that foster motor activity which in turn stimulates the brain towards a state that is beneficial for cognitive task performance. These working environments consist of office desk furnitures that allows or even encourages movement behavior. In the applied research field of neuroergonomics findings from neuroscience and human factors are combined to design working environments that match the affordances and limitations of the human brain and cognitive system (for an overview see Ayaz and Dehais, 2019). One main aim is to detect the underlying brain and cognitive mechanisms that lead to a more efficient and healthy working. Research has focused on the effects of working environment designs on visual attention, vigilance, mental workload, working memory processes, and motor control on brain and cognitive functions (Parasuraman and Rizzo, 2007; Parasuraman and Wilson, 2008; Lees et al., 2010; Gramann et al., 2017). To date, no systematic studies have been performed on the effects of dynamic office furniture use on brain and cognitive functions in everyday working settings. These dynamic office furnitures have specific features that encourage movement behavior, i.e., chairs that allow vertical and horizontal movements during sitting, or desks that alter their height in an automated manner so that subjects have to adapt by altering their posture.

In the present study, we tested the effects of working in a dynamic office environment on EEG brain activity, attentional, and vigilance task performance. According to the results of previous studies (Henz, 2014; Henz et al., 2015), we expected that working in a dynamic office environment would improve attentional and vigilance performance. We hypothesized that working in a dynamic office environment would be accompanied by an increase in processing volume, and a decrease in errors in the attentional task. For the vigilance test, we expected a decrease in reaction times (RTs). Further, working in a dynamic office would activate the brain towards a state that fosters improvements in attentional and vigilance performance compared to working in a static office environment. We expected increases in beta and gamma power, and coherence in frontal electrodes in the attentional and vigilance task. Further, we hypothesized that improvements in attentional and vigilance performance accompanied by increases in beta and gamma power and increased coherence in the would increase after a 2-week intervention. For the EEG coherence analysis, we tested the frontal area, represented by the electrode pairs $F 3 / F 4, F 3 / F z$, and F7/Fz. EEG measured at these frontal electrode sites was assumed to reflect activity in (pre)frontal brain areas involved in executive functions, voluntary control, and action creation (Szurhaj et al., 2003; Moriguchi and Hiraki, 2013), Further, we tested the primary motor area from $\mathrm{C} 3 / \mathrm{Cz}, \mathrm{C} 3 / \mathrm{C} 4$, and $\mathrm{C} 4 / \mathrm{Cz}$ which is related to motor act execution (Toni et al., 2002), and the parietal area from $\mathrm{P} 3 / \mathrm{Pz}$, and $\mathrm{P} 3 / \mathrm{P} 4$ that is involved in sensorimotor integration (Smith et al., 1999; Neuper and Pfurtscheller, 2001; Huber et al., 2006). Our hypotheses are based on findings of recent studies which have shown close interrelations between the motor system and attentional processing. Several investigations have shown increases in beta band activity when the motor network is activated (Khanna and Carmena, 2015; Chung et al., 2017). Beta activity is also eminent in brain areas that are related to attentional processing (Kopell et al., 2000). Synchronization in the beta range was shown in the dorsal prefrontal cortex and posterior parietal cortex in tasks that engage predominantly visual attention (Verhoef et al., 2011; Buschman et al., 2012). Saleh et al. (2010) demonstrated a close relation of beta activity in the motor cortex and beta activity during processing of attentional tasks. 


\section{MATERIALS AND METHODS}

\section{Participants}

Twenty-four subjects (mean age 24.3 years, age range 21-35, 12 males, 12 females) participated in the study. None of the subjects had current neurological diseases or a history of neurological impairments or intake of medication that may have influenced EEG brain activity. All subjects were right-handed. Handedness was assessed by the Edinburgh Handedness Inventory (Oldfield, 1971). Subjects were paid for participation in the study. The study was approved by the local ethics committee of the University of Mainz. All subjects gave written informed consent. All experimental procedures complied with the standards of the Helsinki Declaration of the World Medical Association Assembly. All subjects were naïve as to the purpose of the study.

\section{EEG Recording Details}

EEG brain activity was recorded from 19 electrodes that were placed according to the international 10-20 system on the scalp with reference to the nose. EEG signals were recorded from the electrodes Fp1, Fp2, F3, F7, Fz, F4, F8, C3, Cz, C4, T3, T4, P3, P7, Pz, P4, P8, O1, O2. Electrodes are referred to different scalp areas as follows: frontal area (Fp1, Fp2, F3, $\mathrm{F} 7, \mathrm{Fz}, \mathrm{F} 4, \mathrm{~F} 8)$, central area $(\mathrm{C} 3, \mathrm{Cz}, \mathrm{C} 4)$, temporal area (T3, T4), parietal area (P3, P7, Pz, P4, P8), and occipital area (O1, O2). The Micromed Brainquick amplifier (SD-LTM-32) and Micromed Brainspy software (Micromed, Venice, Italy) were used for the EEG recordings. Impedances of all electrodes were kept at $10 \mathrm{k} \Omega$ or below. EEG data were recorded continuously and digitized at a sampling rate of $256 \mathrm{~Hz}$. EEG signals were amplified with a time constant of $0.3 \mathrm{~s}$ (highpass filter: $0.5 \mathrm{~Hz}$; low pass filter: $120 \mathrm{~Hz}$; frequency range: 0.5-120 Hz). To assess electrooculographic (EOG) data two electrodes were placed at the medial upper and lateral orbital rim of the right eye. EOG signals were amplified with a time constant of $0.3 \mathrm{~s}$ (high pass filter: $0.1 \mathrm{~Hz}$; low pass filter: $120 \mathrm{~Hz}$; frequency range: $0.5-120 \mathrm{~Hz}$ ). Heart rate was measured continuously as a control variable using the medilog ${ }^{\circledR}$ AR12plus recorder (Schiller, Linz, Austria) at a sampling rate of $1,000 \mathrm{~Hz}$. As a further control variable, electromyographic (EMG) activity was recorded using the biovision (Wehrheim,
Germany) from two electrodes placed at the splenius capitis, and two electrodes placed at the trapezius pars descendens at a sampling rate of $500 \mathrm{~Hz}$.

\section{Dynamic and Static Office Environments}

A schematic illustration of the dynamic office environment (active office ${ }^{\circledR}$, aeris $\mathrm{GmbH}$, Munich, Germany) is depicted in Figure 1. It consists of two desks that are heightadjustable with one desk designed as a sitting workstation, and the other as a standing workstation. Subjects sat at the sitting workstation on a height-adjustable stool (swopper ${ }^{\circledR}$, aeris $\mathrm{GmbH}$, Munich, Germany) that allowed subject-induced movements in the vertical direction. At the standing workstation, subjects performed tasks placed on a height-adjustable stool (muvman ${ }^{\circledR}$, aeris $\mathrm{GmbH}$, Munich, Germany) that supports sitting with legs stretched similar to a stance position. Additionally, subjects stood on a foam mat that had an uneven surface structure (aeris ${ }^{\circledR}$ muvmat) at the standing workstation. A $21^{\prime \prime}$ screen was placed on the middle of each desk. One main characteristic of the dynamic office environment is that subjects have to change the workstation at randomly set time intervals ranging from 5 to $20 \mathrm{~min}$. The experimental tasks were arranged in that way that after completion of some sections a signal on the screen appeared that indicated to change the workstation. In contrast, subjects performed the experimental tasks in the static office environment in the same desk configuration but sat only at the sitting workstation on a static stool. The static stool was height-adjustable and had the same properties as the stool used in the dynamic condition except of allowing subject-induced movements in the vertical direction.

\section{Assessment of Attentional and Vigilance Performance}

The experimental tasks are illustrated in Figure 2. For the assessment of short-term attentional performance, subjects performed the $\mathrm{d} 2-\mathrm{R}$ attention test (Brickenkamp et al., 2010). The test sheet of the $\mathrm{d} 2-\mathrm{R}$ test consists of 14 lines with 57 characters each. The characters are the letters " $d$ " and " $p$ ". They are accompanied by different markers consisting of one to four vertical lines that are positioned over or below the characters. The task of the subjects was to scratch all letters
A

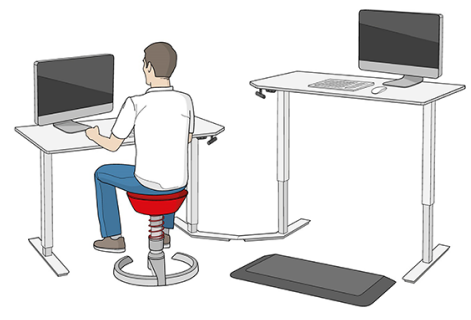

B

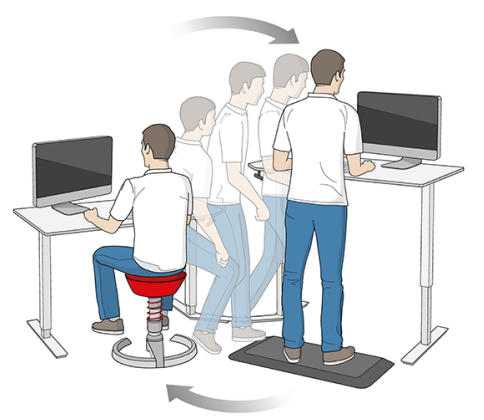

C

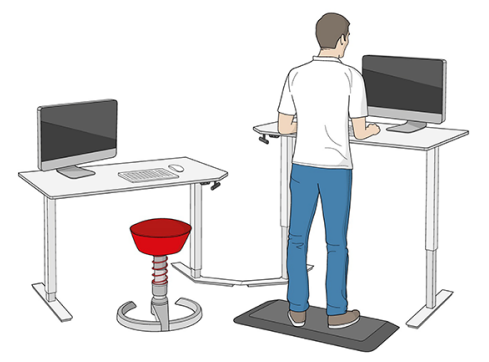

FIGURE 1 | Illustration of the dynamic office environment. (A) Sitting workstation. (B) Change from the sitting to the standing workstation. (C) Standing workstation. 


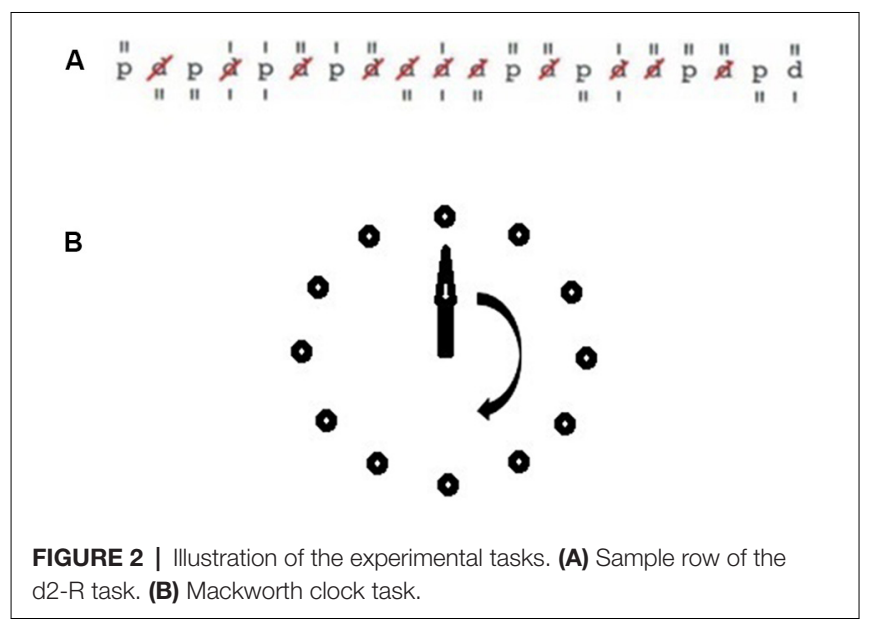

"d" with a total of two lines. Errors consisted of missing to scratch a letter " $\mathrm{d}$ ", the scratching of the letter " $p$ ", and the scratching of a letter " $d$ " with more or less than a total of two lines. The degree of difficulty of the test is composed of the time limit ( $4 \mathrm{~min} 40 \mathrm{~s}$ ) and the challenge to discriminate between relevant and irrelevant stimuli. Vigilance performance was assessed by the Mackworth clock task (Mackworth, 1948). Test stimuli were presented on a screen. Subjects tracked a clock hand visually that moved around the screen passing distinct positions that were arranged circular (diameter $15 \mathrm{~cm}$ ). The task of the subjects was to press a button when the hand jumped more than one position. RTs are calculated from the latency of the hand jump, and the button press. RTs were taken for the segments: (1) minute 1-5; (2) minute 6-10; (3) minute 11-15; and (4) minute 16-20.

\section{Experimental Procedure}

Prior to the experiment, the experimental tasks were explained. Each subject was shown where and how to sit or stand. Half of the subjects performed the intervention in the dynamic office environment, the other half underwent the intervention in the static office environment. Participants were randomly assigned to the experimental groups. After subjects gave their informed consent, demographic data were assessed. Then, they began with a 5-min resting condition. Spontaneous EEG was recorded for $5 \mathrm{~min}$ with eyes-open. Then, subjects were sat at the office environment and performed the experimental tasks. Each intervention session had a duration of $4 \mathrm{~h}$. Subjects performed a standardized program that contained everyday office tasks (E-mail correspondence, calculations, document reading etc.). The $\mathrm{d} 2-\mathrm{R}$ test was performed after $10 \mathrm{~min}$ and after $120 \mathrm{~min}$, the Mackworth clock task after $15 \mathrm{~min}$ and after $125 \mathrm{~min}$ working in the office in the first and in the last session of the 2 -week intervention. Spontaneous EEG was recorded continuously during the six conditions: (1) pre-intervention rest; (2) d2-R test; (3) Mackworth clock task minutes 1-5; (4) Mackworth clock task minutes 6-10; (5) Mackworth clock task minutes 11-15; and (6) Mackworth clock task minutes 16-20 that were used for subsequent statistical analyses.

\section{EEG Analysis}

EEG analyses were performed with the EEGLAB (Swartz Center for Computational Neuroscience, La Jolla, CA, USA). Spontaneous EEG was assessed with eyes-open. Five-minute sequences were recorded before and after each experimental condition. Independent component analyses (ICAs) were performed for the EEG signal. Components that resulted from artifacts were removed. For the analysis of the EEG data, Fast Fourier Transforms were performed to calculate the mean power spectra for the theta $(4-7.5 \mathrm{~Hz})$, alpha $(8-13 \mathrm{~Hz})$, beta $(14-30 \mathrm{~Hz})$, and gamma $(31-70 \mathrm{~Hz})$ bands. Further, EEG coherence for the electrode pairs (F3/F4, $\mathrm{F} 3 / \mathrm{Fz}, \quad \mathrm{F} 7 / \mathrm{Fz}, \mathrm{C} 3 / \mathrm{Cz}, \mathrm{P} 3 / \mathrm{Pz}$, and $\mathrm{P} 3 / \mathrm{P} 4)$ was analyzed. Coherence was calculated for the theta, alpha, beta, and gamma range.

\section{Electrode Spatial Localization}

Three regions of interest were selected: the pre-motor and pre-frontal cortex, represented by the F3/F4, F3/Fz and F7/Fz electrode pairs, which are assumed to be functionally involved in action creation and voluntary control (Moriguchi and Hiraki, 2013), and for executive functions (Szurhaj et al., 2003). The $\mathrm{C} 3 / \mathrm{Cz}, \mathrm{C} 3 / \mathrm{C} 4$ and $\mathrm{C} 4 / \mathrm{Cz}$ electrode pairs were assessed for being representatives of primary motor areas related to the motor act execution (Toni et al., 2002); the P3/Pz and P3/P4 electrode pairs due to their relation to sensorimotor integration (Smith et al., 1999; Huber et al., 2006).

\section{Data on the Attention and Vigilance Task}

Performance in the $\mathrm{d} 2-\mathrm{R}$ test was determined by the attention performance score. It was calculated by subtracting the number of falsely marked test items from the total number of correctly marked characters. Mean RTs in the Mackworth clock task were calculated for four segments: (1) minute 1-5; (2) minute 6-10; (3) minute 11-15; and (4) minute 16-20.

\section{Statistical Analyses}

Means and standard deviations of the $\mathrm{d} 2-\mathrm{R}$ attentional performance score, and the RTs of the Mackworth clock task (minute 1-5, minute 6-10, minute 11-15, minute 16-20) were calculated. Mauchly's test of sphericity was calculated to test the assumptions of repeated-measures analysis of variance (ANOVAs) for the d2-R test score, the RTs of the Mackworth clock task, and the EEG data. Consecutive ANOVAs were performed when the $p$-values were equal or exceeded 0.05 . A two-way ANOVA that included the between-subjects factor working environment (static, dynamic), and the within-subjects factor time (pretest, posttest) was performed for the $\mathrm{d} 2$ - $\mathrm{R}$ test score. Further, a three-way ANOVA that included the betweensubjects factor working environment (static, dynamic), and the within-subjects factors time (pretest, posttest), and segment (minute 1-5, minute 6-10, minute 11-15, minute 16-20) was performed for the RTs of the Mackworth clock task. In a consecutive step, data were subjected to post hoc $t$-tests with Bonferroni-correction. For the EEG data, repeated-measure ANOVAs were performed separately for the theta, alpha, beta, and gamma bands that included the between-subject factor 
working environment (static, dynamic), and the within-subject factors as time (pretest, posttest), experimental condition (pretest rest, vigilance test minute $1-5$, vigilance test minute $6-10$, vigilance test minute 11-15, vigilance test minute 16-20, posttest rest), and location (Frontal, Central, Temporal, Parietal, Occipital). In a consecutive step, post hoc $t$-tests with Bonferronicorrection were calculated for significant main or interaction effects. Additionally, partial eta-squared $\left(\eta_{\mathrm{p}}^{2}\right)$ was calculated to determine effect sizes for the $\mathrm{d} 2-\mathrm{R}$ test score, RTs of the Mackworth clock task, and the frequency specific EEG power densities (theta, alpha, beta, gamma). The coherence values were analyzed using a two-way ANOVA with the factors working environment (static, dynamic), and time (pretest, posttest) for each electrode pair studied (F3/F4, F3/Fz, F7/Fz, C3/Cz, P3/Pz, $\mathrm{P} 3 / \mathrm{P} 4$ and T3/T4). Statistical significance of the tests was achieved when the $p$-values were less than 0.05 .

\section{RESULTS}

\section{Attentional Performance}

Means and standard deviations of the scores of the $\mathrm{d} 2-\mathrm{R}$ test and the Mackworth clock task are depicted in Figures 3, 4. The ANOVA on the attentional performance score of the $\mathrm{d} 2-\mathrm{R}$ test showed a significant effect for the factor working environment after $10 \mathrm{~min}, F_{(1,23)}=5.92, p=0.02, \eta_{\mathrm{p}}^{2}=0.18$. Further, the effect for the factor time was significant, $F_{(1,19)}=7.39, p=0.02$, $\eta_{\mathrm{p}}^{2}=0.21$. The working environment $\times$ time interaction was significant, $F_{(4,19)}=3.14, p=0.03, \eta_{\mathrm{p}}^{2}=0.13$.

The ANOVA for the RTs in the Mackworth clock task revealed a significant effect for working environment, $F_{(1,19)}=4.75, p=0.03, \eta_{\mathrm{p}}^{2}=0.15$. Further, a significant main effect was shown for the factors experimental condition, $F_{(3,57)}=3.81, p=0.02, \eta_{\mathrm{p}}^{2}=0.11$, and time, $F_{(1,19)}=6.03, p=0.02$, $\eta_{\mathrm{p}}^{2}=0.17$. The working environment $\times$ time interaction was significant, $F_{(4,19)}=3.77, p=0.04, \eta_{\mathrm{p}}^{2}=0.06$.

\section{Spontaneous EEG}

Mean power spectra for the EEG theta, alpha, beta, and gamma bands in the $\mathrm{d} 2$ - $\mathrm{R}$ test and the Mackworth clock task are depicted in Figures 5, 6.

The ANOVA for theta power obtained during the Mackworth clock task showed significant main effects for working environment, $F_{(1,19)}=4.92, p=0.03, \eta_{\mathrm{p}}^{2}=0.08$, and time, $F_{(1,19)}=4.53, p=0.04, \eta_{\mathrm{p}}^{2}=0.05$. The working environment $\times$ time interaction was significant, $F_{(4,19)}=2.96$, $p=0.04, \eta_{\mathrm{p}}^{2}=0.03$. A further ANOVA revealed significant differences between locations, $F_{(20,95)}=2.16, p=0.02, \eta_{\mathrm{p}}^{2}=0.13$. Post hoc comparisons showed increases in EEG theta power at frontal, central, and parietal electrodes, compared to temporal and occipital electrodes, $p<0.05$ each. Subsequent analyses showed that theta power increased most in the frontal region at the electrodes $\mathrm{F} 3$ and $\mathrm{F} 4, p<0.05$ each.

The ANOVA for alpha power obtained during the Mackworth clock task showed a significant main effects for working environment, $F_{(1,19)}=5.96, p=0.02, \eta_{\mathrm{p}}^{2}=0.14$, and time, $F_{(1,19)}=6.16, p=0.02, \eta_{\mathrm{p}}^{2}=0.15$. The working environment $\times$ time interaction was significant, $F_{(4,19)}=3.02$,

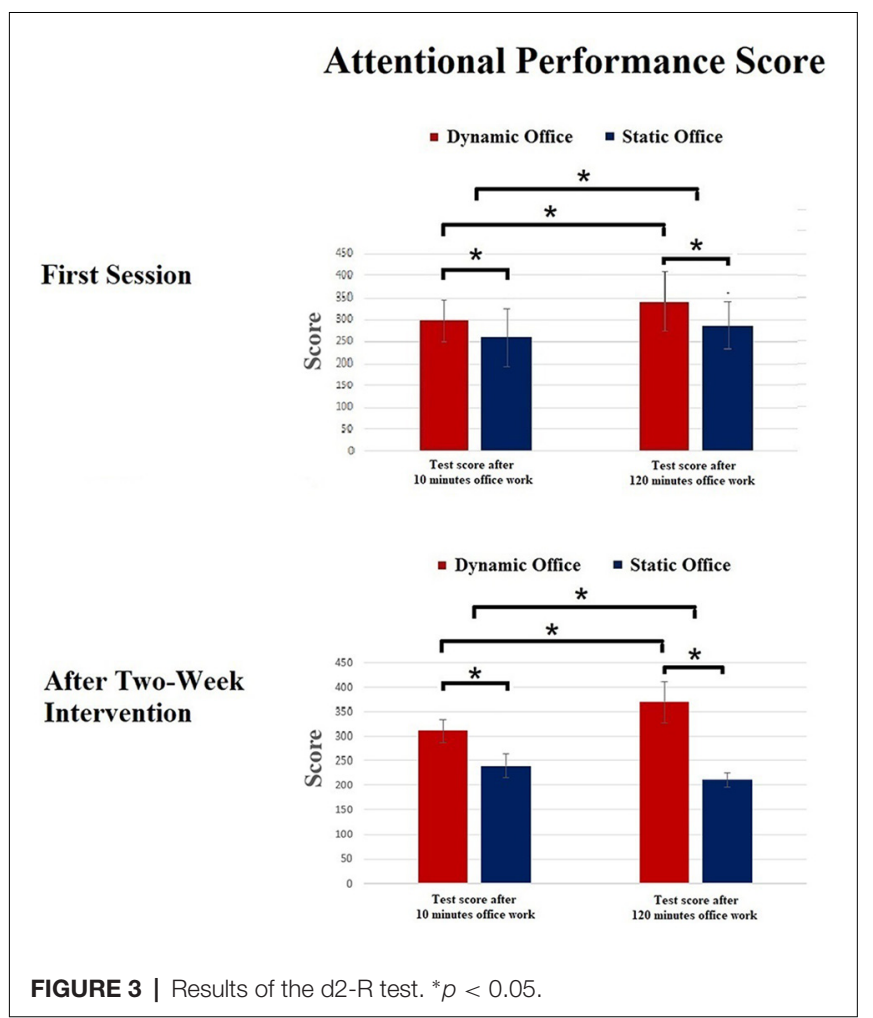

First Session

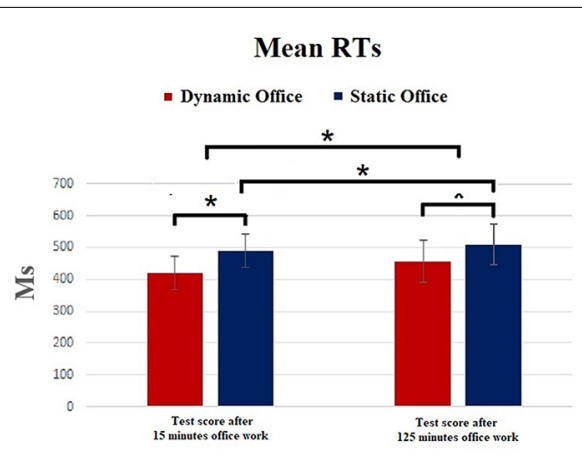

After Two-Week

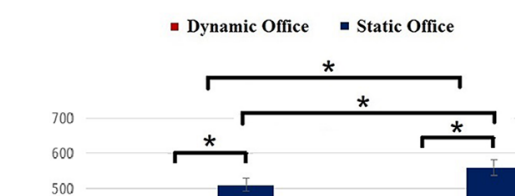

Intervention

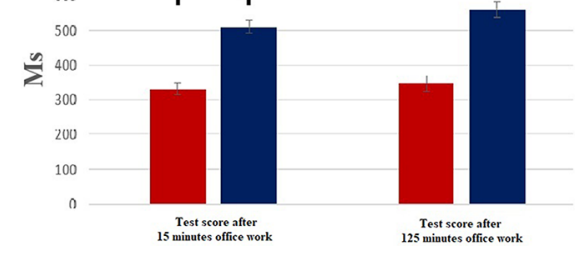

FIGURE 4 | Results of the Mackworth clock task. ${ }^{*} p<0.05$.

$p=0.03, \eta_{\mathrm{p}}^{2}=0.12$. The ANOVA of alpha responses revealed significant differences between locations, $F_{(20,95)}=1.90, p=0.04$, $\eta_{\mathrm{p}}^{2}=0.05$. Post hoc comparisons showed that spontaneous EEG 


\title{
Dynamic Office
}

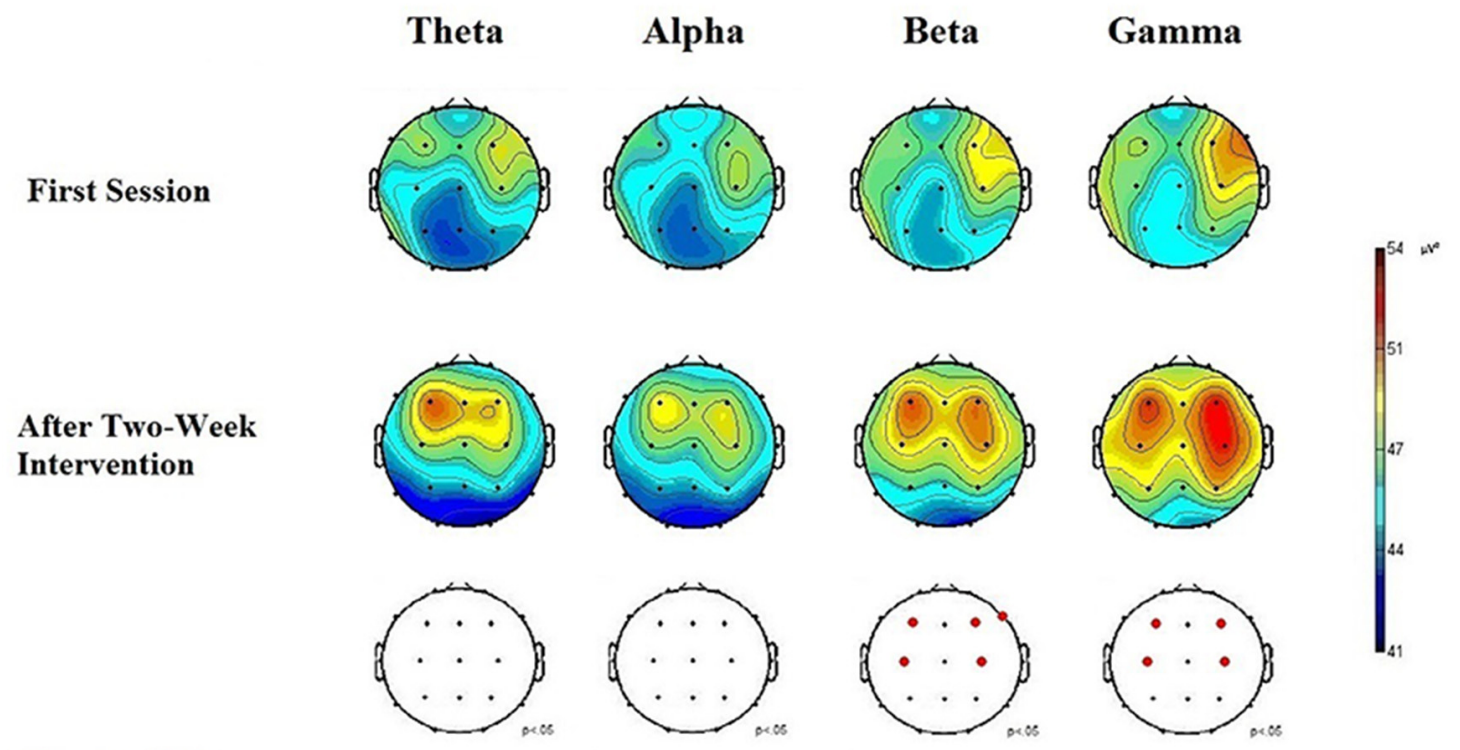

\section{Static Office}

\author{
First Session
After Two-Week Intervention
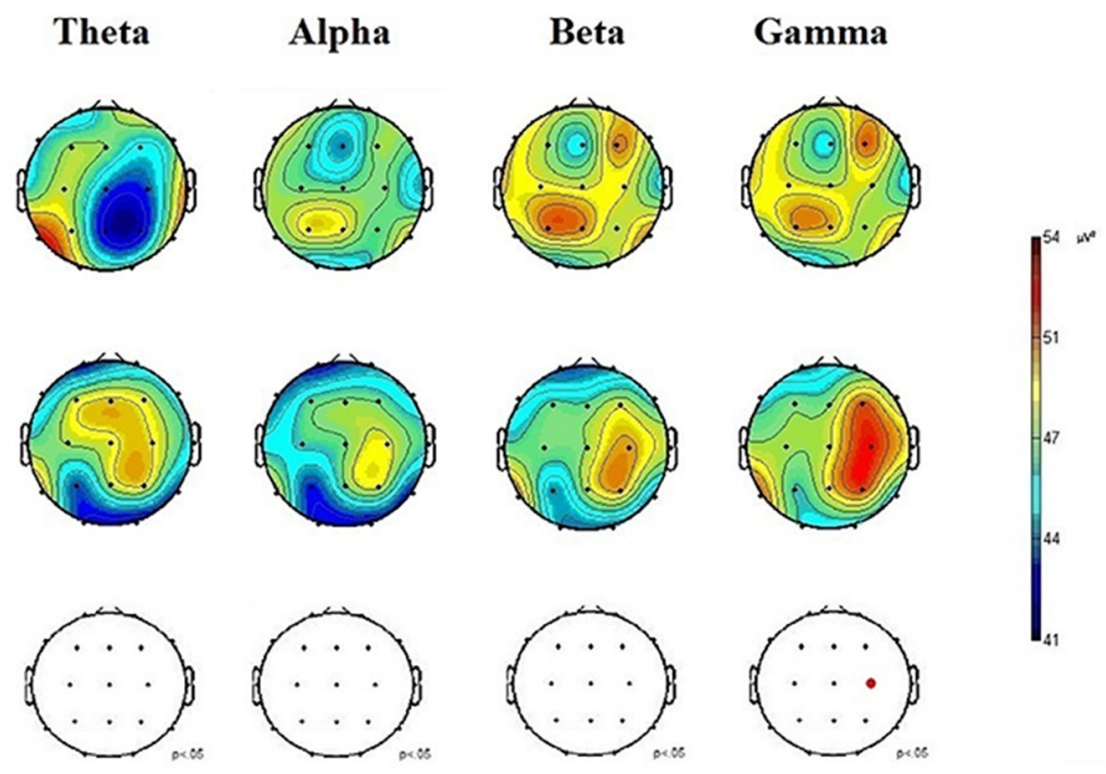

FIGURE 5 | Electroencephalographic (EEG) brain activity for the theta, alpha, beta, and gamma bands in the dynamic and static office during the d2-R test.

alpha power was higher at central and parietal electrodes, than that of frontal, temporal, and occipital electrodes, $p<0.05$ each. Subsequent analyses showed that alpha power increased most in the central region at the electrode $\mathrm{C} 4$, and in the parietal region at the electrodes $\mathrm{P} 3$ and $\mathrm{P} 4, p<0.05$ each.

The ANOVA for beta power obtained during the $d 2-R$ test showed highly significant main effects for the factors working environment, $F_{(1,19)}=8.45, p=0.01, \eta_{\mathrm{p}}^{2}=0.25$, and time, $F_{(1,19)}=8.37, p=0.01, \eta_{\mathrm{p}}^{2}=0.22$. The working environment $\times$ time interaction was significant, $F_{(4,19)}=3.84$, $p=0.02, \eta_{\mathrm{p}}^{2}=0.18$. The ANOVA of beta responses revealed highly significant differences between locations, $F_{(20,95)}=2.83$, $p=0.009, \eta_{\mathrm{p}}^{2}=0.28$. Post hoc comparisons showed that spontaneous EEG beta power was higher at frontal and central electrodes, than that of parietal, temporal, and occipital electrodes, $p<0.05$ each. Subsequent analyses showed that beta power increased most in the frontal region at the electrodes F3, $\mathrm{F} 4$, and F8, $p<0.01$ each, and in the central region at the 


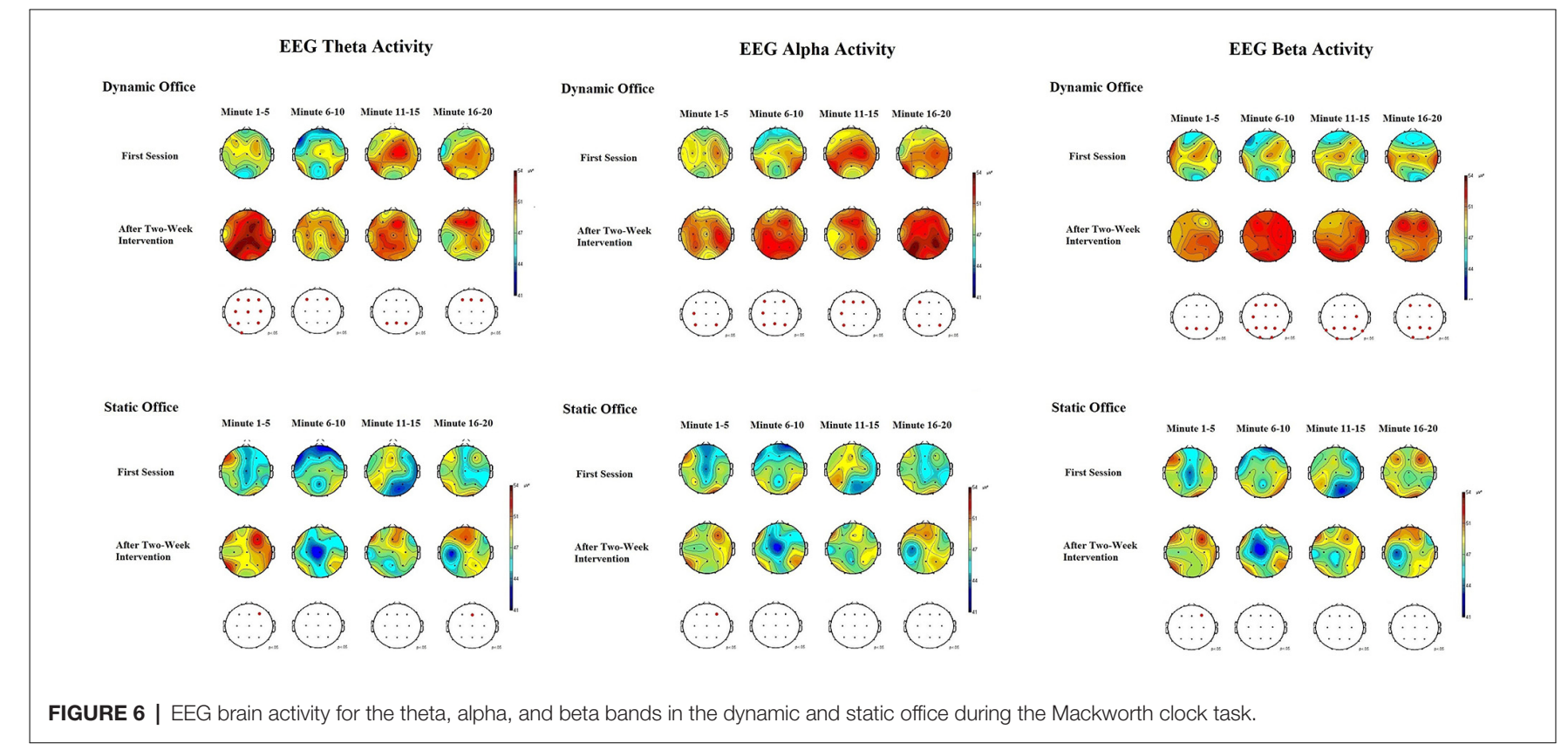

electrodes C3 and C4, $p<0.05$ each. The ANOVA for beta activity obtained during the Mackworth clock task showed highly significant main effects for the factors working environment, $F_{(1,19)}=8.48, p=0.01, \eta_{\mathrm{p}}^{2}=0.27$, and time, $F_{(1,19)}=8.25, p=0.01$, $\eta_{\mathrm{p}}^{2}=0.24$. The working environment $\times$ time interaction was significant, $F_{(5,95)}=3.28, p=0.03, \eta_{\mathrm{p}}^{2}=0.17$.

The ANOVA for gamma power obtained during the $\mathrm{d} 2-\mathrm{R}$ test showed significant main effects for working environment, $F_{(1,19)}=5.17, p=0.02, \eta_{\mathrm{p}}^{2}=0.10$, and time, $F_{(1,19)}=5.03, p=0.03$, $\eta_{\mathrm{p}}^{2}=0.08$. The working environment $\times$ time interaction was significant, $F_{(4,19)}=3.38, p=0.03, \eta_{\mathrm{p}}^{2}=0.10$. The ANOVA of gamma responses revealed a highly significant difference between locations, $F_{(20,95)}=2.79, p=0.008, \eta_{\mathrm{p}}^{2}=0.28$. Post hoc comparisons showed that spontaneous EEG gamma power increased at frontal and central electrodes, compared to that of parietal, temporal, and occipital electrodes, $p<0.05$ each. Subsequent analyses showed that gamma power increased most in the frontal region at the electrodes F3 and F4, $p<0.05$, and in the central region at the electrodes $\mathrm{C} 3$ and $\mathrm{C} 4, p<0.05$ each.

\section{EEG Coherence}

For the theta range, highly significant main effects were found in the Mackworth clock task for the electrode pairs F3/F4, $F_{(1,19)}=10.71, p=0.01$, and $\mathrm{P} 3 / \mathrm{P} 4, F_{(1,19)}=14.82, p=0.008$, with a coherence increase in the dynamic office, when compared to the static office. Further, highly significant main effects were found for the factor time for the electrode pairs F3/F4, $F_{(1,19)}=9.75, p=0.01$, and P3/P4, $F_{(1,19)}=10.48, p=0.009$, with increases in theta coherence in the posttest, when compared to pretest. The working environment $\times$ time interactions were significant for F3/F4, $F_{(4,19)}=3.27, p=0.02$, and $\mathrm{P} 3 / \mathrm{P} 4$, $F_{(4,19)}=4.22, p=0.02$.

Analysis on the alpha range showed significant main effects in the Mackworth clock task for the electrode pairs F3/F4,
$F_{(1,19)}=5.62, p=0.03$, and P3/P4, $F_{(1,19)}=6.81, p=0.02$, with coherence increases in the dynamic office, when compared to the static office. Further, significant main effects were found for the factor time for the electrode pairs $\mathrm{F} 3 / \mathrm{F} 4, F_{(1,19)}=4.88$, $p=0.04$, and $\mathrm{P} 3 / \mathrm{P} 4, F_{(1,19)}=5.74, p=0.03$, with increases in alpha coherence in the posttest, when compared to pretest. The working environment $\times$ time interactions were significant for $\mathrm{F} 3 / \mathrm{F} 4, F_{(4,19)}=4.02, p=0.02$, and $\mathrm{P} 3 / \mathrm{P} 4, F_{(4,19)}=5.82, p=0.03$.

For the beta range, significant main effects were found in the Mackworth clock task for the electrode pairs F3/F4, $F_{(1,19)}=8.02, p=0.02$, and C $3 / \mathrm{C} 4, F_{(1,19)}=7.87, p=0.02$, with a coherence increase in the dynamic office, when compared to the static office. Further, main effects were found for the factor time for the electrode pairs $\mathrm{F} 3 / \mathrm{F} 4, F_{(1,19)}=7.53, p=0.02$, and $\mathrm{C} 3 / \mathrm{C} 4, F_{(1,19)}=7.96, p=0.02$, with increases in beta coherence in the posttest, when compared to pretest. The working environment $\times$ time interactions were significant for $\mathrm{F} 3 / \mathrm{F} 4, F_{(4,19)}=3.90, p=0.03$, and $\mathrm{C} 3 / \mathrm{C} 4, F_{(1,19)}=4.05$, $p=0.02$. Further for the $\mathrm{d} 2-\mathrm{R}$ task, highly significant main effects were found for the electrode pairs F3/F4, $F_{(1,19)}=10.57$, $p=0.009$, and $\mathrm{C} 3 / \mathrm{C} 4, F_{(1,19)}=8.73, p=0.01$, with a coherence increase in the dynamic office, when compared to the static office. Further, significant main effects were found for the factor time for the electrode pairs $\mathrm{F} 3 / \mathrm{F} 4$, $F_{(1,19)}=7.80, p=0.02$, and $\mathrm{C} 3 / \mathrm{C} 4, F_{(1,19)}=6.33, p=0.02$, with increases in beta coherence in the posttest, when compared to pretest. The working environment $\times$ time interactions were significant for $\mathrm{F} 3 / \mathrm{F} 4, F_{(4,19)}=3.98, p=0.03$, and $\mathrm{C} 3 / \mathrm{C} 4$, $F_{(4,19)}=3.25, p=0.03$.

Analysis on the gamma range showed highly significant main effects in the $\mathrm{d} 2-\mathrm{R}$ task for the electrode pairs $\mathrm{F} 3 / \mathrm{F} 4$, $F_{(1,19)}=10.23, p=0.009$, and $\mathrm{P} 3 / \mathrm{P} 4, F_{(1,19)}=9.27, p=0.01$, with coherence increases in the dynamic office, when compared to the static office. Further, a highly significant main effects was found 
for the factor time for the electrode pairs $\mathrm{F} 3 / \mathrm{F} 4, F_{(1,19)}=11.06$, $p=0.008$, and $\mathrm{P} 3 / \mathrm{P} 4, F_{(1,19)}=8.97, p=0.01$, with increases in gamma coherence in the posttest, when compared to pretest. The working environment $x$ time interactions were significant for $\mathrm{F} 3 / \mathrm{F} 4, F_{(4,19)}=5.38, p=0.01$, and $\mathrm{P} 3 / \mathrm{P} 4, F_{(4,19)}=3.86, p=0.02$.

\section{DISCUSSION}

This is the first study that investigated the effects of a dynamic office environment on EEG brain oscillations and attentional as well as vigilance performance. Results clearly demonstrate distinguishable patterns of EEG brain oscillations when working in the dynamic compared to working in the static office. Attentional performance increased in the dynamic office compared to working in the static office after $120 \mathrm{~min}$. Moreover, attentional and vigilance performance increased after the 2-week intervention in the dynamic office. Brain oscillatory patterns showed increased beta and gamma power in frontal (F4), and parietal $(\mathrm{P} 3, \mathrm{Pz})$ areas in the attentional task in the dynamic office. Theta, alpha, and beta power increased in frontal (F3, Fz, $\mathrm{F} 4)$, central (C3), and parietal (P3, Pz, P4) areas in the vigilance task when working in the dynamic office. Further, analyses revealed increased interhemispheric coherence for the electrode pairs $\mathrm{F} 3 / \mathrm{F} 4, \mathrm{C} 3 / \mathrm{C} 4$, and P3/P4 in the dynamic office. Effects on brain oscillatory patterns increased after the 2-week intervention in the dynamic office. We found increased EEG alpha, beta, and gamma power in the $\mathrm{d} 2-\mathrm{R}$ task as compared to pretest. Further, EEG theta, alpha, and beta power were higher in the vigilance task than at pretest. EEG data on coherence demonstrated increased interhemispheric coherence for the electrode pairs F3/F4, C3/C4, and $\mathrm{P} 3 / \mathrm{P} 4$ at posttest.

Our results expand findings from previous neurophysiological investigations on the beneficial effects of dynamic sitting on cognitive functions and brain oscillations (Henz et al., 2015; Henz and Schöllhorn, 2016). In these studies, we showed increases in visuo-spatial and working memory task performance when sitting on a chair that allowed movements during working compared to working on a static chair. As a neural correlate for improved task performance, we found increases in alpha and beta power in brain areas that are related to visuo-spatial and working memory processes. We argued that these improvements are mediated by increased motor activity in the dynamic sitting condition.

The obtained patterns of EEG brain oscillations indicate different underlying neural processes during working in a dynamic office versus working in a static office environment. In the following sections, we discuss different lines of interpretations on the obtained patterns of brain oscillations.

\section{Dynamic Office Environments Enhance Brain Oscillations Related to Attentional Processing}

Brain oscillations before and after the 2-week intervention in the dynamic office showed increases in frontal (F3, F4), central (C3), and parietal (P3, P4) theta, alpha, and beta band activity during the vigilance task compared to pretest. Coherence analysis showed increased interhemispheric coherence for the derivations $\mathrm{F} 3 / \mathrm{F} 4, \mathrm{C} 3 / \mathrm{C} 4$, and $\mathrm{P} 3 / \mathrm{P} 4$. We argue that the observed brain oscillatory patterns are a correlate for modulations of attentional processes during working in the dynamic office. Previous studies have demonstrated that frontal cortexes are related to executive functions, voluntary control, and action creation (Jung et al., 2000; Cardoso de Oliveira, 2002). Theta activity was shown to be related to these behaviors that demand action planning based on received sensory information (Liepert et al., 1998; Caplan et al., 2003). These studies show a relation between theta band coherence with attention and movement preparation.

Results on increased EEG theta power during the Mackworth clock task are in line with findings of a study by Pennekamp et al. (1994). They showed increases in performance in the Mackworth clock task that were accompanied by increases in theta activity. Several studies have shown that the allocation of attentional resources is accompanied by distinct brain activation patterns. Enhanced theta activity in frontal brain areas is currently discussed as a neural substrate for improvements of cognitive control (Chung et al., 2017). More specifically, theta oscillations in frontal brain areas are observed in the early allocation of selective attention resources on external visual stimuli. This frontal theta activity appears to improve cognitive control during visuo-motor tasks (Berchicci et al., 2015). Increases in theta activity are shown in goal-directed attention (Dowdall et al., 2012). Stimulus-induced changes in the theta, alpha, and beta bands have been shown to be a correlate for modulation of goal-directed spatial attention (Harris et al., 2017). More specifically, EEG oscillations occurred either in the theta, alpha, and beta range in the involuntary capture of goal-directed visual attention. The authors found a lateralization in the theta band related to the processing of goal-relevant and goal-irrelevant stimuli. Lateralization in the alpha band was shown for goal-directed attention. Further, beta oscillations were not location-specific. Several studies have shown that alpha activity in parietal regions is involved in the processing of visual stimuli (Jensen et al., 2012; Roux and Uhlhaas, 2014; Foster et al., 2016). Further, there is evidence for a relation between alpha oscillations and voluntary attentional allocation (Worden et al., 2000; Kelly et al., 2006; Thut et al., 2006; Foxe and Snyder, 2011).

\section{Relations Between Increased Motor Activity and Attention}

Attentional and vigilance performance increased in the dynamic compared to the static office. Analysis on the corresponding power spectra and coherence analysis revealed increased activity in the frontal areas that are related to executive functions, voluntary control, and action planning (Szurhaj et al., 2003; Moriguchi and Hiraki, 2013). Further, brain areas related to motor act execution showed increased oscillatory activity. Increased coherence in $\mathrm{C} 3 / \mathrm{C} 4$ is associated with motor act execution (Papenberg et al., 2013), motor act organization (Minc et al., 2010), and sequential movement coordination (Coull et al., 1998). Such findings show that motor activity and executive processes are closely related.

Current research shows close interrelations between attentional processing and posture control. Recent studies using 
a dual-task paradigm indicate that sensorimotor processing is essential to postural control, and requires attentional resources (Boisgontier et al., 2013). Several investigations reveal that even highly practiced postural tasks require cognitive processing at least to a small degree. For instance, Tsang et al. (2016) have shown that the simultaneous performance of a cognitive task during quiet stance resulted in an increase in postural sway. Beta activity has been shown in attention and long-distance synchronization in parts of the cortex. For instance, synchronization of beta activity was demonstrated in the dorsal prefrontal cortex and posterior parietal cortex during a top-down search of a visual stimulus (Buschman and Miller, 2007; Buschman et al., 2012; Verhoef et al., 2011). Beta activation in motor areas is a neural substrate for attention to upcoming motor tasks. Brain activation patterns in the beta range are not limited to the activity of the motor cortex and EMG, but play also an important role in somatosensory and parietal areas (Witham and Baker, 2007; Tsujimoto et al., 2009). Further, coherence between the motor and afferent sensory areas is shown to operate at the beta frequency (Baker, 2007). Saleh et al. (2010) demonstrated a close link between beta activity in the motor cortex and attention. Further, beta activity indicates selectively coordinated cell-assemblies that are task-relevant (Kopell et al., 2000). EEG beta activity also plays an important role in attentional processing (Wróbel et al., 2007; Sauseng and Klimesch, 2008). Recent studies suggest that EEG beta activity is necessary to enhance feedback loops at subsequent stages of visual information processing (i.e., Gola et al., 2013). Beta activity and connectivity in the sensorimotor and parietal cortex are essential for accurate motor performance (Chung et al., 2017).

A further line of argumentation considers the role of alpha and beta activation in self-initiated movements. Wang et al. (2017) found increases in alpha activity in the SMA in self-initiated movements. Further, they demonstrated increases in sensorimotor areas in the alpha and beta bands in self-initiated and visually guided movements.

Finally, we found increases in gamma power during the attentional task when working in the dynamic office. We interpret these results in terms of an enhancing effect of motor activity on attentional processing. Increases in gamma oscillations are found in selective attentional processing (Engel and Singer, 2001; Varela et al., 2001). From this, we argue that performing attentional tasks in a dynamic office environment stimulates executive cognitive controlled processing. This interpretation is in line with studies that showed enhancement of executive functions by gross motor movements (i.e., Benzinger et al., 2018). Further, evidence shows that gamma band activity of frontal and central areas is associated with memory encoding (Sederberg et al., 2003), motor memory tasks (Gentili et al., 2015), and encoding of motor memory in dynamic motor adaptation tasks (Thürer et al., 2016).

In summary, several studies have shown that theta, alpha, and beta frequencies play dissociable roles in visual attention. Increases in gamma power were found as a correlate for selective attention. From this, we interpret the increases in the theta, alpha, and beta oscillations in the vigilance task, and the increases in the alpha, beta, and gamma bands in the attentional task as indicators for modulations of visual attention that result from increased motor activity when working in a dynamic office that fosters physical activity.

\section{Working in a Dynamic Environment Reinforces Visuo-Spatial Working Memory Processes and Multisensory Integration}

Increases in theta band oscillations have also been discussed as an indicator for visuo-spatial working memory processes (Bastiaansen et al., 2002). Further, resource allocation is one of the cognitive processes that are located within working memory models. Increases in theta power in somatosensory and motor brain areas during working in the dynamic office might be a correlate for working memory processes (Carretié, 2001; Mitchell et al., 2008; Myers et al., 2014; Tóth et al., 2014), and a neurophysiological substrate for encoding of new information (Klimesch et al., 1996, 1997; Klimesch, 1999; Bastiaansen et al., 2002). In previous studies, we found enhancement of visuospatial abilities in geometrical and algebraic tasks during sitting on a chair that allowed vertical and horizontal movements during sitting. Enhanced performance was accompanied by increases in frontal theta activity (Henz, 2014; Henz et al., 2015). We argued that better performance in geometrical and algebraic tasks resulted from stimulation of the visuo-spatial working memory system by bodily movements.

A further line of interpretation is that increases in theta and alpha coherence reflect processes of multisensory integration in the brain that afford working memory processes (see Kanayama et al., 2015). For instance, Hummel and Gerloff (2005) demonstrated increases in alpha coherence during a crossmodal matching task. The authors argue that the EEG alpha coherence is a correlate for synchronization processes of brain areas that are related to cross-modal integration. Classen et al. (1998) showed increased EEG coherence between visual and somatosensory brain areas as well as between visual and motor areas during a visuo-motor tracking task. Further studies have shown increased theta coherence in the derivations $\mathrm{P} 3 / \mathrm{Pz}$, and $\mathrm{P} 3 / \mathrm{P} 4$ which are involved in sensorimotor integration (Smith et al., 1999; Neuper and Pfurtscheller, 2001; Huber et al., 2006). Several studies show that processing of whole-body movements is accompanied by modulations in alpha band activity. Gutteling and Medendorp (2016) demonstrated that the processing of bodily motion is mirrored by a modulation in central and parietal areas, whereas visual target coding was shown in power modulation in parieto-occipital areas. Summarizing, the parietal cortex is involved in both the processing of bodily motion, and spatial processing, consistent with its role as a brain region that integrates information from visual, motor and vestibular signals (Zhang and Britten, 2011; Gale et al., 2015; Gutteling et al., 2015).

\section{Increased Fluctuations Stimulate Brain Functions and Attentional Performance}

A different theoretical perspective on the effects of increased motor activity on brain oscillatory patterns and attentional performance could be applied considering theoretical assumptions of the system dynamic theory (Haken, 1970; Glansdorff and Prigogine, 1971; Haken et al., 1985). Bodily 
movements that change continuously during task performance and problem solving might lead to increased fluctuations and deviations during task solving. Several scientific approaches refer to the term deviation from a predefined ideal state. From this perspective, the term deviation has a rather negative connotation. In contrast, the system dynamic approach considers deviations rather as constructive fluctuations. They are defined as a more neutral term that is derived from stochastic physics. According to the system dynamic approach, systems that are characterized to have energetic or material exchange with an environment show continuous fluctuations. Another hypothesis derived from the system dynamic approach is that an increase of fluctuations that causes a period of instability is necessary to stimulate transitions from one stable state to another state in these systems. During phase transitions, these systems explore a variety of modes in order to find new and even more effective states. These phenomena have been investigated extensively in different areas of sports and everyday movements (Kelso, 1995; Davids et al., 2006). Recent neurophysiological studies have shown that increased fluctuations in the human body induced by differential movement training increased learning rates that were accompanied by brain oscillations in the theta and alpha range (Henz and Schöllhorn, 2016; Henz et al., 2018). Instead of considering increases in fluctuations as a passive ontological phenomenon of dissipative systems, the differential training approach takes advantage of increased system fluctuations as an active instrument in order to lead the system towards a zone of instability where less energy is needed for achieving a self-organized new state (Schöllhorn, 1999, 2000; Schöllhorn et al., 2006, 2009, 2010, 2012). One implication of these previous findings is that increased fluctuations in the human body induced by randomly performed movements enhance a state of brain oscillatory activity that is characterized by increased theta and alpha power which reinforces creative solutions in sports

\section{REFERENCES}

Ayaz, H., and Dehais, F. (2019). Neuroergonomics: The Brain at Work and Everyday Life. 1st Edn. Elsevier: Academic Press. Available online at: https://www.sciencedirect.com/book/9780128119266/neuroergonomics. [Accessed on March 19, 2019].

Baker, S. N. (2007). Oscillatory interactions between sensorimotor cortex and the periphery. Curr. Opin. Neurobiol. 17, 649-655. doi: 10.1016/j.conb.2008.01.007

Bastiaansen, M. C., Posthuma, D., Groot, P. F., and de Geus, E. J. (2002). Event-related $\alpha$ and theta responses in a visuo-spatial working memory task. Clin. Neurophysiol. 113, 1882-1893. doi: 10.1016/s1388-2457(02) 00303-6

Berchicci, M., Pontifex, M. B., Drollette, E. S., Pesce, C., Hillman, C. H., and Di Russo, F. (2015). From cognitive motor preparation to visual processing: the benefits of childhood fitness to brain health. Neuroscience 298, 211-219. doi: 10 . 1016/j.neuroscience.2015.04.028

Brickenkamp, R., Schmidt-Atzert, L., and Liepmann, D. (2010). d2-R. Test d2Revision. Aufmerksamkeits- und Konzentrationstest. Göttingen: Hogrefe.

Benzinger, V., Chang, Y. K., and Schmidt, M. (2018). Acute physical activity enhances executive functions in children with ADHD. Sci. Rep. 8:12382. doi: 10.1038/s41598-018-30067-8

Boisgontier, M. P., Beets, I. A. M., Duysens, J., Nieuwboer, A., Krampe, R. T., and Swinnen, S. P. (2013). Age-related differences in attentional cost associated with postural dual tasks increased recruitment of generic cognitive resources in older adults. Neurosci. Biobehav. Rev. 37, 1824-1837. doi: 10.1016/j.neubiorev. 2013.07.014
(Santos et al., 2018) as well as during problem solving (Fink et al., $2007,2009)$ in working and school settings.

\section{CONCLUSION}

The results of the present study reveal short- and mid-term effects on attentional and vigilance performance, and EEG brain activity when working in a dynamic versus a static environment. During working in a dynamic office, attentional and vigilance performance increased compared to working in a static office. Brain activities show increased alpha, beta and gamma power in the frontal and central areas in the attentional task with increased theta, alpha, and beta activity in the vigilance task. These findings suggest that working in a dynamic office environment stimulates the brain towards an optimum psychophysiological level of activation and wakefulness for attentional and vigilance performance. The results of the present study are of relevance in the field of neuroergonomics, for the design of office and school working environments and encourage the use of dynamic office desk furniture that allows movements during working to achieve increased attentional as well as vigilance performance.

\section{ETHICS STATEMENT}

The study was approved by the local ethics committee of the University of Mainz. All subjects gave written informed consent. All experimental procedures complied with the standards of the Helsinki Declaration of the World Medical Association Assembly. All subjects were naïve as to the purpose of the study.

\section{AUTHOR CONTRIBUTIONS}

All listed authors made substantial and intellectual contributions to the manuscript.

Brümmer, V., Schneider, S., Abel, T., Vogt, T., and Strüder, H. (2011). Brain cortical activity is influenced by exercise mode and intensity. Med. Sci. Sports Exerc. 43, 1863-1872. doi: 10.1249/mss.0b013e3182172a6f

Brunoni, A. R., Lopes, M., and Fregni, F. (2008). A systematic review and metaanalysis of clinical studies on major depression and BDNF levels: implications for the role of neuroplasticity in depression. Int. J. Neuropsychopharmacol. 11, 1169-1180. doi: 10.1017/s1461145708009309

Buschman, T. J., Denovellis, E. L., Diogo, C., Bullock, D., and Miller, E. K. (2012). Synchronous oscillatory neural ensembles for rules in the prefrontal cortex. Neuron 76, 838-846. doi: 10.1016/j.neuron.2012.09.029

Buschman, T. J., and Miller, E. K. (2007). Top-down versus bottom-up control of attention in the prefrontal and posterior parietal cortices. Science 315, 1860-1862. doi: 10.1126/science.1138071

Caplan, J. B., Madsen, J. R., Schulze-Bonhage, A., Aschenbrenner-Scheibe, R., Newman, E. L., and Kahana, M. J. (2003). Human $\theta$ oscillations related to sensorimotor integration and spatial learning. J. Neurosci. 23, 4726-4736. doi: 10.1523/JNEUROSCI.23-11-04726.2003

Cardoso de Oliveira, S. (2002). The neuronal basis of bimanual coordination: recent neurophysiological evidence and functional models. Acta Psychol. 110, 139-159. doi: 10.1016/s0001-6918(02)00031-8

Carretié, L. A. (2001). Psicofisiología. Madrid: Ediciones Pirámide.

Chang, Y. K., Labban, J. D., Gapin, J. I., and Etnier, J. L. (2012). The effects of acute exercise on cognitive performance. Brain Res. 1453, 87-101. doi: 10.1016/j. brainres.2012.02.068

Chieffi, S., Messina, G., Villano, I., Messina, A., Valenzano, A., Moscatelli, F., et al. (2017). Neuroprotective effects of physical activity: evidence from 
human and animal studies. Front. Neurol. 8:188. doi: 10.3389/fneur.2017. 00188

Chung, J. W., Ofori, E., Misra, G., Hess, C. W., and Vaillancourt, D. E. (2017). $\beta$-band activity and connectivity in sensorimotor and parietal cortex are important for accurate motor performance. Neuroimage 144, 164-173. doi: 10.1016/j.neuroimage.2016.10.008

Classen, J., Liepert, J., Wise, S. P., Hallett, M., and Cohen, L. G. (1998). Rapid plasticity of human cortical movement representation induced by practice. J. Neurophysiol. 79, 1117-1123. doi: 10.1152/jn.1998.79.2.1117

Colberg, S. R., Somma, C. T., and Sechrist, S. R. (2008). Physical activity participation may offset some of the negative impact of diabetes on cognitive function. J. Am. Med. Dir. Assoc. 9, 434-438. doi: 10.1016/j.jamda.2008. 03.014

Colcombe, S. J., Erickson, K. I., Scalf, P. E., Kim, J. S., Prakash, R., McAuley, E., et al. (2006). Aerobic exercise training increases brain volume in aging humans. J. Gerontol. A Biol. Sci. Med. Sci. 61, 1166-1170. doi: 10.1093/gerona/61.11.1166

Colcombe, S., and Kramer, A. F. (2003). Fitness effects on the cognitive function of older adults. Psychol. Sci. 14, 125-130. doi: 10.1111/1467-9280.t01-1-01430

Coull, J. T., Frackowiak, R. S., and Frith, C. D. (1998). Monitoring for target objects: activation of right frontal and parietal cortices with increasing time on task. Neuropsychologia 36, 1325-1334. doi: 10.1016/s0028-3932(98)00035-9

Davids, K., Button, C., Araújo, D., Renshaw, I., and Hristovski, R. (2006). Movement models from sports provide representative task constraints for studying adaptive behavior in human motor systems. Adapt. Behav. 14, 73-95. doi: 10.1177/105971230601400103

Deeny, S. P., Poeppel, D., Zimmerman, J. B., Roth, S. M., Brandauer, J., Witkowski, S., et al. (2008). Exercise, APOE, and working memory: MEG and behavioral evidence for benefit of exercise in epsilon4 carriers. Biol. Psychol. 78, 179-187. doi: 10.1016/j.biopsycho.2008.02.007

Dowdall, J. R., Luczak, A., and Tata, M. S. (2012). Temporal variability of the N2pc during efficient and inefficient visual search. Neuropsychologia 50, 2442-2453. doi: 10.1016/j.neuropsychologia.2012.06.015

Engel, A. K., and Singer, W. (2001). Temporal binding and the neural correlates of sensory awareness. Trends Cogn. Sci. 5, 16-25. doi: 10.1016/s13646613(00)01568-0

Etnier, J. L., Salazar, W., Landers, D. M., Petruzzello, S. J., Han, M., and Nowell, P. (2004). The influence of physical fitness and exercise upon cognitive functioning: a meta-analysis. J. Sport Exerc. Psychol. 19, 249-277. doi: 10.1123/jsep.19.3.249

Fink, A., Benedek, M., Grabner, R. H., Staudt, B., and Neubauer, A. C. (2007). Creativity meets neuroscience: experimental tasks for the neuroscientific study of creative thinking. Methods 42, 68-76. doi: 10.1016/j.ymeth.2006.12.001

Fink, A., Grabner, R. H., Benedek, M., Reishofer, G., Hauswirth, V., Fally, M., et al. (2009). The creative brain: investigation of brain activity during creative problem solving by means of EEG and fMRI. Hum. Brain Mapp. 30, 734-748. doi: $10.1002 / \mathrm{hbm} .20538$

Foster, J. J., Sutterer, D. W., Serences, J. T., Vogel, E. K., and Awh, E. (2016). The topography of alpha-band activity tracks the content of spatial working memory. J. Neurophysiol. 115, 168-177. doi: 10.1152/jn.00860.2015

Foxe, J. J., and Snyder, A. C. (2011). The role of alpha-band brain oscillations as a sensory suppression mechanism during selective attention. Front. Psychol. 2:154. doi: 10.3389/fpsyg.2011.00154

Gale, S., Prsa, M., Schurger, A., Gay, A., Paillard, A., Herbelin, B., et al. (2015). Oscillatory neural responses evoked by natural vestibular stimuli in humans. J. Neurophysiol. 115, 1228-1242. doi: 10.1152/jn.00153.2015

Gentili, R. J., Bradberry, T. J., Oh, H., Costanzo, M. E., Kerick, S. E., ContrerasVidal, J. L., et al. (2015). Evolution of cerebral cortico-cortical communication during visuomotor adaptation to a cognitive-motor executive challenge. Biol. Psychol. 105, 51-65. doi: 10.1016/j.biopsycho.2014.12.003

Gheysen, F., Poppe, L., DeSmet, A., Swinnen, S., Cardon, G., De Bourdeaudhuij, I., et al. (2018). Physical activity to improve cognition in older adults: can physical activity programs enriched with cognitive challenges enhance the effects? A systematic review and meta-analysis. Int. J. Behav. Nutr. Phys. Act. 15:63. doi: 10.1186/s12966-018-0697-x

Glansdorff, P., and Prigogine, I. (1971). Thermodynamics Theory of Structure, Stability and Fluctuations. London: Wiley-Interscience.

Gola, M., Magnuski, M., Szumska, I., and Wróbel, A. (2013). EEG beta band activity is related to attention and attentional deficits in the visual performance of elderly subjects. Int. J. Psychophysiol. 89, 334-341. doi: 10.1016/j.ijpsycho. 2013.05.007

Gramann, K., Fairclough, S. H., Zander, T. O., and Ayaz, H. (2017). Trends in neuroergonomics: a comprehensive overview. Front. Hum. Neurosci. 11:165. doi: 10.3389/fnhum.2017.00165

Grego, F., Vallier, J. M., Collardeaul, M., Rousseu, C., Cremieux, J., and Brisswalter, J. (2005). Influence of exercise duration andhydration status on cognitive function during prolonged cyclingexercise. Int. J. Sports Med. 26, 27-33. doi: 10.1055/s-2004-817915

Gutteling, T. P., and Medendorp, W. P. (2016). Role of alpha-band oscillations in spatial updating across whole body motion. Front. Psychol. 7:671. doi: 10. 3389/fpsyg.2016.00671

Gutteling, T. P., Selen, L. P. J., and Medendorp, W. P. (2015). Parallax-sensitive remapping of visual space in occipito-parietal alpha-band activity during whole-body motion. J. Neurophysiol. 113, 1574-1584. doi: 10.1152/jn.00477. 2014

Haken, H. (1970). "Laser theory," in Light and Matter Ic/Licht und Materie Ic, ed. L. Genzel (Berlin: Springer), 1-304. Available online at: https://link.springer. com/chapter/10.1007/978-3-662-22091-7_1. [Accessed on March 19, 2019].

Haken, H., Kelso, J. A. S., and Bunz, H. (1985). A theoretical model of phase transitions in human hand movements. Biol. Cybern. 51, 347-356. doi: $10.1007 /$ bf00336922

Harris, A. M., Dux, P. E., Jones, C. N., and Mattingley, J. B. (2017). Distinct roles of theta and alpha oscillations in the involuntary capture of goal-directed attention. Neuroimage 152, 171-183. doi: 10.1016/j.neuroimage.2017. 03.008

Henz, D. (2014). EEG brain activity in algebraic, geometric, and numerical reasoning tasks under static and dynamic postural control. Psychophysiology 55:58.

Henz, D., John, A., Merz, C., and Schöllhorn, W. I. (2018). Post-task EEG brain activations differ for various contextual interference and differential training protocols. Front. Hum. Neurosci. 12:19. doi: 10.3389/fnhum.2018.00019

Henz, D., Oldenburg, R., and Schöllhorn, W. I. (2015). "Does bodily movement enhance mathematical performance? Behavioral and neurophysiological evidence," in Proceedings of the 9th Conference on Research in Mathematics Education (Chicago, IL: ACM), 1-10.

Henz, D., and Schöllhorn, W. I. (2016). Differential training facilitates early consolidation in motor learning. Front. Behav. Neurosci. 10:199. doi: 10.3389/fnbeh.2016.00199

Huber, R., Ghilardi, M. F., Massimini, M., Ferrarelli, F., Riedner, B. A., Peterson, M. J., et al. (2006). Arm immobilization causes cortical plastic changes and locally decreases sleep slow wave activity. Nat. Neurosci. 9, 1169-1176. doi: $10.1038 / \mathrm{nn} 1758$

Hummel, F., and Gerloff, C. (2005). Larger interregional synchrony is associated with greater behavioral success in a complex sensory integration task in humans. Cereb. Cortex 15, 670-678. doi: 10.1093/cercor/bhh170

Jensen, O., Bonnefond, M., and VanRullen, R. (2012). An oscillatory mechanism for prioritizing salient unattended stimuli. Trends Cogn. Sci. 16, 200-206. doi: $10.1016 /$ j.tics.2012.03.002

Jung, T. P., Makeig, S., Westerfield, M., Townsend, J., Courchesne, E., and Sejnowski, T. J. (2000). Removal of eye activity artifacts from visual eventrelated potentials in normal and clinical subjects. Clin. Neurophysiol. 111, 1745-1758. doi: 10.1016/s1388-2457(00)00386-2

Kanayama, N., Kimura, K., and Hiraki, K. (2015). Cortical EEG components that reflect inverse effectiveness during visuo tactile integration processing. Brain Res. 1598, 18-30. doi: 10.1016/j.brainres.2014.12.017

Kelly, S. P., Lalor, E. C., Reilly, R. B., and Foxe, J. J. (2006). Increases in alpha oscillatory power reflect an active retinotopic mechanism for distracter suppression during sustained visuospatial attention. J. Neurophysiol. 95, 3844-3851. doi: 10.1152/jn.01234.2005

Kelso, J. A. S. (1995). Dynamic Patterns: The Self-Organization of Brain and Behavior. Cambridge, MA: MIT Press.

Khanna, P., and Carmena, J. M. (2015). Neural networks: $\beta$ band activity across motor networks. Curr. Opin. Neurobiol. 32, 60-67. doi: 10.1016/j.conb.2014. 11.010

Klimesch, W. (1999). EEG $\alpha$ and theta oscillations reflect cognitive and memory performance: a review and analysis. Brain Res. Rev. 29, 169-195. doi: 10.1016/s0165-0173(98)00056-3 
Klimesch, W., Doppelmayr, M., Russegger, H., and Pachinger, T. (1996). Theta band power in the human scalp EEG and the encoding of new information. Neuroreport 7, 1235-1240. doi: 10.1097/00001756-199605170-00002

Klimesch, W., Doppelmayr, M., Schimke, H., and Ripper, B. (1997). Theta synchronization and $\alpha$ desynchronization in a memory task. Psychophysiology 34, 169-176. doi: 10.1111/j.1469-8986.1997.tb02128.x

Kopell, N., Ermentrout, G. B., Whittington, M. A., and Traub, R. D. (2000). Gamma rhythms and beta rhythms have different synchronization properties. Proc. Natl. Acad. Sci. U S A 97, 1867-1872. doi: 10.1073/pnas.97.4.1867

Kramer, A. F., Hahn, S., Cohen, N. J., Banich, M. T., McAuley, E., Harrison, C. R., et al. (1999). Ageing, fitness and neurocognitive function. Nature 400, 418-419. doi: $10.1038 / 22682$

Lees, M. N., Cosman, J. D., Lee, J. D., Fricke, N., and Rizzo, M. (2010). Translating cognitive neuroscience to the driver's operational environment: a neuroergonomic approach. Am. J. Psychol. 123, 391-411. doi: 10.5406/amerjpsyc.124.4.0391

Liepert, J., Miltner, W. H., Bauder, H., Sommer, M., Dettmers, C., Taub, E., et al. (1998). Motor cortex plasticity during constraint-induced movement therapy in stroke patients. Neurosci. Lett. 250, 5-8. doi: 10.1016/s0304-3940(98) 00386-3

Mandolesi, L., Polverino, A., Montuori, S., Foti, F., Ferraioli, G., Sorrentino, P., et al. (2018). Effects of physical exercise on cognitive functioning and wellbeing: biological and psychological benefits. Front. Psychol. 9:509. doi: 10.3389/fpsyg. 2018.00509

Minc, D., Machado, S., Bastos, V. H., Machado, D., Cunha, M., Cagy, M., et al. (2010). $\gamma$ band oscillations under influence of bromazepam during a sensorimotor integration task: an EEG coherence study. Neurosci. Lett. 469, 145-149. doi: 10.1016/j.neulet.2009.11.062

Mitchell, D. J., McNaughton, N., Flanagan, D., and Kirk, I. J. (2008). Frontalmidline theta from the perspective of hippocampal "theta". Prog. Neurobiol. 86, 156-185. doi: 10.1016/j.pneurobio.2008.09.005

Moraes, H., Deslandes, A., Silveira, H., Ribeiro, P., Cagy, M., Piedade, R., et al. (2011). The effect of acute effort on EEG in healthy young and elderly subjects. Eur. J. Appl. Physiol. 111, 67-75. doi: 10.1007/s00421-010-1627-z

Moraes, H., Ferreira, C., Deslandes, A., Cagy, M., Pompeu, F., Ribeiro, P., et al. (2007). $\beta$ and $\alpha$ electroencephalographic activity changes after acute exercise. Arq. Neuropsiquiatr. 65, 637-641. doi: 10.1590/s0004-282x20070004 00018

Moriguchi, Y., and Hiraki, K. (2013). Prefrontal cortex and executive function in young children: a review of NIRS studies. Front. Hum. Neurosci. 7:867. doi: $10.3389 /$ fnhum. 2013.00867

Myers, N. E., Stokes, M. G., Walther, L., and Nobre, A. C. (2014). Oscillatory brain state predicts variability in working memory. J. Neurosci. 34, 7735-7743. doi: 10.1523/JNEUROSCI.4741-13.2014

Neuper, C., and Pfurtscheller, G. (2001). Event-related dynamics of cortical rhythms: frequency-specific features and functional correlates. Int. J. Psychophysiol. 43, 41-58. doi: 10.1016/s0167-8760(01)00178-7

Oldfield, R. C. (1971). The assessment and analysis of handedness: the Edinburgh inventory. Neuropsychologia 9, 97-113. doi: 10.1016/0028-3932(71)90067-4

Papenberg, G., Hämmerer, D., Müller, V., Lindenberger, U., and Li, S. C. (2013). Lower theta inter-trial phase coherence during performance monitoring is related to higher reaction time variability: a lifespan study. Neuroimage 83, 912-920. doi: 10.1016/j.neuroimage.2013.07.032

Parasuraman, R., and Rizzo, M. (2007). Neuroergonomics. The Brain at Work. New York, NY: Oxford University Press.

Parasuraman, R., and Wilson, G. F. (2008). Putting the brain to work: neuroergonomics past, present, and future. Hum. Fact. 50, 468-474. doi: $10.1518 / 001872008 \times 288349$

Pennekamp, P., Bosel, R., Mecklinger, A., and Ott, H. (1994). Differences in EEG-theta for responded and omitted targets in a sustained attention task. J. Psychophysiol. 8, 131-141.

Pereira, T., Cipriano, I., Costa, T., Saraiva, M., and Martins, A. (2019). Exercise, ageing and cognitive function-effects of a personalized physical exercise program in the cognitive function of older adults. Physiol. Behav. 202, 8-13. doi: 10.1016/j.physbeh.2019.01.018

Roux, F., and Uhlhaas, P. J. (2014). Working memory and neural oscillations: alpha-gamma versus theta-gamma codes for distinct WM information? Trends Cogn. Sci. 18, 16-25. doi: 10.1016/j.tics.2013.10.010
Saleh, M., Reimer, J., Penn, R., Ojakangas, C. L., and Hatsopoulos, N. G. (2010). Fast and slow oscillations in human primary motor cortex predict oncoming behaviorally relevant cues. Neuron 65, 461-471. doi: 10.1016/j.neuron.2010. 02.001

Santos, S., Coutinho, D., Gonçalves, B., Schöllhorn, W., Sampaio, J., and Leite, N. (2018). Differential learning as a key training approach to improve creative and tactical behavior in soccer. Res. Q. Exerc. Sport 89, 11-24. doi: 10.1080/02701367.2017.1412063

Sauseng, P., and Klimesch, W. (2008). What does phase information of oscillatory brain activity tell us about cognitive processes? Neurosci. Biobehav. Rev. 32, 1001-1013. doi: 10.1016/j.neubiorev.2008.03.014

Schöllhorn, W. I. (1999). Individualität-ein vernachlässigter Parameter? Leistungssport 29, 7-11. [Individuality-a neglected parameter? Comp. Sports 29, 7-11.

Schöllhorn, W. I. (2000). Applications of systems dynamic principles to technique and strength training. Acta Acad. Olympiquae Estoniae 8, 67-85.

Schöllhorn, W. I., Beckmann, H., Janssen, D., and Drepper, J. (2010). "Stochastic perturbations in athletics field events enhance skill acquisition," in Motor Learning in Practice. A Constraints-Led Approach, eds I. Renshaw, K. Davids and G. J. P. Savelsbergh (London: Routledge), 69-82.

Schöllhorn, W. I., Hegen, P., and Davids, K. (2012). The nonlinear nature of learning-a differential learning approach. Open Sports Sci. J. 5, 100-112. doi: $10.2174 / 1875399 \times 01205010100$

Schöllhorn, W. I., Michelbrink, M., Beckmann, H., Trockel, M., Sechelmann, M., and Davids, K. (2006). Does noise provide a basis for the unification of motor learning theories? Int. J. Sports Psychol. 37, 34-42.

Schöllhorn, W. I., Michelbrink, M., Welminski, D., and Davids, D. (2009). "Increasing stochastic perturbations enhance skill acquisition and learning of complex sport movements," in Perspectives on Cognition and Action in Sport, eds D. Araujo, H. Ripolland and M. Raab (Hauppauge, NY: Nova Science), 59-73.

Sederberg, P. B., Kahana, M. J., Howard, M. W., Donner, E. J., and Madsen, J. R. (2003). Theta and gamma oscillations during encoding predict subsequent recall. J. Neurosci. 23, 10809-10814. doi: 10.1523/JNEUROSCI.23-34-10809. 2003

Sibley, B. A., and Etnier, J. L. (2003). The relationship between physical activity and cognition in children: a meta-analysis. Pediatr. Exerc. Sci. 15, 243-256. doi: 10.1123/pes.15.3.243

Smith, M. E., McEvoy, L. K., and Gevins, A. (1999). Neurophysiological indices of strategy development and skill acquisition. Cogn. Brain Res. 7, 389-404. doi: 10. 1016/s0926-6410(98)00043-3

Szurhaj, W., Derambure, P., Labyt, E., Cassim, F., Bourriez, J. L., Isnard, J., et al. (2003). Basic mechanisms of central rhythms reactivity to preparation and execution of a voluntary movement: a stereoelectroencephalographic study. Clin. Neurophysiol. 114, 107-119. doi: 10.1016/s1388-2457(02)00333-4

Thürer, B., Stockinger, C., Focke, A., Putze, F., Schultz, T., and Stein, T. (2016). Increased gamma band power during movement planning coincides with motor memory retrieval. Neuroimage 125, 172-181. doi: 10.1016/j.neuroimage. 2015.10.008

Thut, G., Nietzel, A., Brandt, S. A., and Pascual-Leone, A. (2006). Alpha-band electroencephalographic activity over occipital cortex indexes visuospatial attention bias and predicts visual target detection. J. Neurosci. 26, 9494-9502. doi: 10.1523/JNEUROSCI.0875-06.2006

Tóth, B., Kardos, Z., File, B., Boha, R., Stam, C. J., and Molnár, M. (2014). Frontal midline theta connectivity is related to efficiency of WM maintenance and is affected by aging. Neurobiol. Learn. Mem. 114, 58-69. doi: 10.1016/j.nlm.2014. 04.009

Toni, I., Shah, N. J., Fink, G. R., Thoenissen, D., Passingham, R. E., and Zilles, K. (2002). Multiple movement representations in the human brain: an event-related fMRI study. J. Cogn. Neurosci. 14, 769-784. doi: $10.1162 / 08989290260138663$

Tsang, W.-W., Chan, V. W.-L., Wong, H. H., Yip, T. W.-C., and Lu, X. (2016). The effect of performing a dual-task on postural control and selective attention of older adults when stepping backward. J. Phys. Ther. Sci. 28, 2806-2811. doi: $10.1589 /$ jpts.28.2806

Tsujimoto, S., Genovesio, A., and Wise, S. P. (2009). Monkey orbitofrontal cortex encodes response choices near feedback time. J. Neurosci. 29, 2569-2574. doi: 10.1523/JNEUROSCI.5777-08.2009 
Varela, F., Lachaux, E., Rodriguez, E., and Martinerie, J. (2001). The brainweb: phase synchronization and large-scale integration. Nat. Rev. Neurosci. 2, 229-239. doi: 10.1038/35067550

Verhoef, B. E., Vogels, R., and Janssen, P. (2011). Synchronization between the end stages of the dorsal and the ventral visual stream. J. Neurophysiol. 105, 2030-2042. doi: 10.1152/jn.00924.2010

Wang, B. A., Viswanathan, S., Abdollahi, R. O., Rosjat, N., Popovych, S., Daun, S., et al. (2017). Frequency-specific modulation of connectivity in the ipsilateral sensorimotor cortex by different forms of movement initiation. Neuroimage 117, 248-260. doi: 10.1016/j.neuroimage.2017.07.054

Weinberg, R. S., and Gould, D. (2015). Foundations of Sport and Exercise Psychology. 6th Edn. Champaign, IL: Human Kinetics.

Winter, B., Breitenstein, C., Mooren, F. C., Voelker, K., Fobker, M., Lechtermann, A., et al. (2007). High impact running improves learning. Neurobiol. Learn. Mem. 87, 597-609. doi: 10.1016/j.nlm.2006.11.003

Witham, C. L., and Baker, S. N. (2007). Network oscillations and intrinsic spiking rhythmicity do not covary in monkey sensorimotor areas. J. Physiol. 580, 801-814. doi: 10.1113/jphysiol.2006.124503

Worden, M. S., Foxe, J. J., Wang, N., and Simpson, G. V. (2000). Anticipatory biasing of visuospatial attention indexed by retinotopically specific $\alpha$-band electroencephalogray increases over occipital cortex. J. Neurosci. 20, 1-6. doi: 10.1523/JNEUROSCI.20-06-j0002.2000

Wróbel, A., Ghazaryan, A., Bekisz, M., Bogdan, W., and Kamiński, J. (2007). Two streams of attention-dependent $\beta$ activity in the striate recipient zone of cat's lateral posterior- pulvinar complex. J. Neurosci. 27, 2230-2240. doi: 10.1523/JNEUROSCI.4004-06.2007

Zhang, T., and Britten, K. H. (2011). Parietal area VIP causally influences heading perception during pursuit eye movements. J. Neurosci. 31, 2569-2575. doi: 10. 1523/JNEUROSCI.5520-10.2011

Conflict of Interest Statement: The authors declare that the research was conducted in the absence of any commercial or financial relationships that could be construed as a potential conflict of interest.

Copyright (c) 2019 Henz and Schöllhorn. This is an open-access article distributed under the terms of the Creative Commons Attribution License (CC BY). The use, distribution or reproduction in other forums is permitted, provided the original author(s) and the copyright owner(s) are credited and that the original publication in this journal is cited, in accordance with accepted academic practice. No use, distribution or reproduction is permitted which does not comply with these terms. 